\title{
LA CLÁUSULA COMPROMISORIA COMO EXCEPCIÓN EN LOS PROCESOS EJECUTIVOS: UNA TESIS SOBRE SU IMPROCEDENCIA
}

\author{
The arbitration clause as an exception in executive proceedings: a thesis \\ on its inadmissibility \\ Adrián Barreto Lezama ${ }^{1}$
}

Recibido: 20 de abril de 2020 - Aceptado: 22 de mayo de 2020

\begin{abstract}
RESUMEN
El presente artículo expone las bases teóricas que tratan de sustentar la improcedencia de la cláusula compromisoria como excepción en los procesos ejecutivos, a partir de la consideración de la naturaleza misma del proceso arbitral, el cual es eminentemente declarativo, y en consideración a las facultades expresamente conferidas por la ley a los árbitros, lo que supone la imposibilidad de ventilar en sede arbitral procesos de naturaleza ejecutiva, aunque haya una cláusula que expresamente señale que las controversias suscitadas con base en ese contrato deberán ser ventiladas ante un tribunal de arbitramento.
\end{abstract}

Palabras clave: Clausula compromisoria; Excepciones; Proceso ejecutivo; Proceso declarativo; Proceso arbitral.

\begin{abstract}
This article sets out the theoretical bases that try to sustain the inadmissibility of the arbitration clause as an exception in executive proceedings, based on the consideration of the nature of the arbitration process itself, which is eminently declarative, and in consideration of the powers expressly conferred by law on arbitrators, which means that it is impossible to deal with executive proceedings in arbitration, even if there is a clause that expressly states that the controversies raised based on that contract must be heard before an arbitration tribunal.
\end{abstract}

Keywords: Arbitration clause; Exceptions; Executive process; declaratory process; Arbitration process.

\footnotetext{
${ }^{1}$ Abogado de la Universidad de Cartagena. Especialista en Derecho Procesal de la Universidad Libre de Colombia. Maestrante en Derecho de la Universidad de Cartagena. Asesor en defensa judicial de entidades públicas, Derecho administrativo y Derecho contractual público. Orcid: https://orcid.org/0000-0002-3211-3603 Email: barretolezamaconsultores@ gmail.com
} 


\section{INTRODUCCIÓN}

En virtud de la cláusula compromisoria contractual, las partes que intervienen en el contrato acuerdan resolver las diferencias surgidas con ocasión del mismo ante un tribunal de arbitramento, el cual, actuando conforme a las facultades otorgadas por las partes, debe poner fin al diferendo. Frente a obligaciones de naturaleza ejecutivas, esto supone la idea de permitir que los árbitros, que son particulares temporalmente investidos de poderes jurisdiccionales (así se desprende del artículo 116 de Constitución Política de Colombia, y de los artículos 7 y 8 de la Ley 1563 de 2012), asuman facultades de ejecución, las cuales según lo dispone la ley, son una función exclusiva del Estado. Conviene resaltar en cuanto a este aspecto, que no se habla de la función jurisdiccional en general, si no de exclusivas facultades de ejecución, pues sobre el primer aspecto está claro que la Ley Estatutaria de la Administración de Justicia eliminó cualquier duda que se pudiera suscitar al respecto, al indicar en su artículo 13 lo relativo al ejercicio de la función jurisdiccional por otras autoridades y por particulares (López, 2016).

Los tribunales de arbitramento por su misma naturaleza son temporales, los particulares como administradores de justicia tienen un límite en el tiempo, toda vez que su actividad está circunscrita al término que las partes, o en su defecto la ley, señala para el ejercicio de la tarea arbitral, resultando en consecuencia incompatible con la naturaleza de proceso ejecutivo que solo termina cuando se satisface el pago de la obligación.

Resulta, pues, necesario diferenciar entre el proceso ejecutivo y aquel de naturaleza declarativa, atendiendo a que el proceso arbitral es de naturaleza declarativa y no comprende la ejecución de obligaciones; mientras que el proceso ejecutivo, persigue el cumplimiento de una obligación clara, expresa y exigible, no siendo el proceso arbitral el mecanismo jurídico para obtener el cumplimiento de una obligación de esta naturaleza, más aun en consideración a los instrumentos de que dispone el acreedor en el marco del proceso para garantizar el pago de la obligación.

\section{i. Consideraciones generales en torno al proceso ejecutivo y sus presupuestos}

Sea lo primero decir que conforme lo prescrito en el artículo 422 del Código General del Proceso, por medio del proceso ejecutivo se busca el cumplimiento de obligaciones claras, expresas y exigibles, contenidas en documentos provenientes del deudor o su causante y que constituya plena prueba contra él, o las que emanen de una sentencia de condena proferida por el juez o tribunal de cualquier jurisdicción, o de otra providencia judicial que tenga fuerza ejecutiva conforme a ley y que el deudor no realizó en su debida oportunidad, respaldado en un documento que constituya plena prueba contra el deudor, sin que haya duda de su autenticidad y sin que sea menester complementarlo con otro elemento de convicción, como se verá más adelante.

En ese sentido, el proceso ejecutivo es aquel por el cual se persigue satisfacer prácticamente, mediante un acto positivo o negativo -obligación de hacer o de no hacer- o el patrimonio de otra persona, un interés jurídico reconocido a favor del demandante o del causante de éste y a cargo de aquella o de su causante, en sentencia de condena o en un título ejecutivo del cual emane en forma clara y expresa y que reúna los demás requisitos que la ley exige (Echandía, 1991). 
Adrián Barreto Lezama

El proceso ejecutivo, llamado también proceso de ejecución y anteriormente de simple ejecución, es un procedimiento para la realización de las pretensiones de prestación (de condena), o por responsabilidad, mediante coacción estatal. La ejecución forzosa quiere llevar a efecto las pretensiones de prestación (de condena) o de responsabilidad del derecho material a favor del interesado, llamado acreedor, contra el obligado, llamado deudor, contenidas en el título ejecutivo (que por sí mismo hace ejecutable la prestación en ella contenida) mediante coacción estatal (Rosemberg, 1955).

Las definiciones expuestas permiten arribar a las notas vertebrales y distintivas del proceso ejecutivo, sobre la idea de que el proceso ejecutivo está sustentado en un derecho cierto, respaldado en un título que ostenta mérito ejecutivo y que, por tanto, permite la ejecución forzosa del acreedor, incluso ordenándose pagar la suma adeudada sin su previa anuencia. Asimismo, el proceso ejecutivo encuentra todo su sustento en la ley, ya que es esta y no los particulares o el juez, la que define el alcance, forma y contenido de los denominados títulos ejecutivos, y también las formas propias del proceso ejecutivo en cuanto procedimiento especial. Desde esa óptica, el objeto del proceso ejecutivo es hacer efectivo un derecho existente, reconocido en una prueba preconstituida (Monroy, 1984).

Es por ello que, en este tipo de procesos, el principal presupuesto para la acción lo constituye el título ejecutivo, por lo que, desde un comienzo, debe probarse la existencia formal y material de un documento o de un conjunto de documentos que contengan los requisitos previstos en la ley, que otorguen certeza legal o presuntiva del derecho del acreedor para reclamar del deudor el cumplimiento de una obligación.

Así pues, todo juicio de ejecución presupone la existencia de un interés insatisfecho, y al igual que en el proceso declarativo, se contraponen dos partes cuyos intereses están en conflicto, pero a diferencia de este último, en el proceso ejecutivo se parte de la certeza inicial del derecho del demandante que no necesita ser declarado, toda vez que consta en un documento al que la ley atribuye el carácter de prueba integral del crédito, de allí entonces, que su titular pretenda a través del mismo, la tutela de su derecho ante la renuencia del obligado, empleando la fuerza legítima del aparato jurisdiccional. Ahora bien, para que un documento tenga el carácter de título ejecutivo, deberá constituir plena prueba contra el deudor, sin que haya duda de su autenticidad y sin que sea menester complementarlo con otro elemento de convicción, tal como se anotó con anterioridad.

El título ejecutivo debe reunir ciertas condiciones formales, las cuales consisten en que el documento o conjunto de documentos que dan cuenta de la existencia de la obligación $i$ ) sean auténticos y ii) emanen del deudor o de su causante, de una sentencia de condena proferida por el juez o Tribunal de cualquier jurisdicción, o de otra providencia judicial que tenga fuerza ejecutiva de conformidad con la ley.

De igual manera se ha señalado que también deben acreditarse condiciones sustanciales, las cuales se traducen en que las obligaciones por cuyo cumplimiento se adelanta el proceso sean claras, expresas y exigibles, conceptos estos que se definen así: La obligación es expresa cuando aparece nítida y manifiesta de la redacción misma del título; es clara cuando 
se revela fácilmente en el título; y es exigible cuando puede lograrse su cumplimiento porque no está sometida a plazo o condición.

Al respecto, la Corte Suprema de Justicia enseña:

"Los requisitos impuestos a los títulos ejecutivos, consignados en el artículo 422 del Código General del Proceso, relativos a tratarse de un documento proveniente del deudor o de su causante en donde conste una obligación clara, expresa y exigible, por supuesto se trasladan a los títulos valores y, en esa medida, si el instrumento no satisface tales presupuestos, no puede seguir adelante el cobro coercitivo.

'La claridad de la obligación, consiste en que el documento que la contenga sea inteligible, inequívoco y sin confusión en el contenido y alcance obligacional de manera que no sea oscuro con relación al crédito a favor del acreedor y la deuda respecto del deudor. Que los elementos de la obligación, sustancialmente se encuentren presentes: Los sujetos, el objeto y el vínculo jurídico. Tanto el préstamo a favor del sujeto activo, así como la acreencia en contra y a cargo del sujeto pasivo.

'La expresividad, como característica adicional, significa que la obligación debe ser explícita, no implícita ni presunta, salvo en la confesión presunta de las preguntas asertivas. No se trata de que no haya necesidad de realizar argumentaciones densas o rebuscadas para hallar la obligación, por cuanto lo meramente indicativo o implícito o tácito al repugnar con lo expreso no puede ser exigido ejecutivamente. Tampoco de suposiciones o de formulación de teorías o hipótesis para hallar el título. Y es exigible en cuanto la obligación es pura y simple o de plazo vencido o de condición cumplida". (Corte Suprema de Justicia, Sentencia STC3298, 2019).

En cuanto al procedimiento se refiere, habiéndose presentado demanda ejecutiva, con el lleno de los requisitos de ley, el Juez deberá proceder a librar mandamiento de pago o lo que es lo mismo, ordenar al ejecutado que cumpla con la obligación respaldada en el título que se aporta como prueba de la misma. Tal como lo indica la norma (artículo 430 C.G.P.) los requisitos formales del título solo podrán discutirse mediante recurso de reposición contra el mandamiento de pago y no se admitirá ninguna controversia sobre los requisitos del mismo que no haya sido planteada mediante este recurso. Las excepciones, siendo el mecanismo de defesa del ejecutado, por medio de las cuales puede presentar las razones para desvirtuar la existencia de la obligación, deben ser presentadas y argumentadas ampliamente y en debida forma, exponiendo su sustento y sus motivos, como lo señala López (2002, p. 544):

"Ciertamente, si yo afirmo que no existe el derecho pretendido o niego los hechos, sin determinar exactamente los motivos de tal posición, estoy a mitad de camino; procesalmente tal conducta es indiferente, pues decir que el derecho no existe es tanto como afirmar que existe; como tesis que son, lo que admite controversia en su sustentación y no la simple enunciación". 
Adrián Barreto Lezama

Si prosperan los argumentos exceptivos, el juez revocará el mandamiento de pago y el ejecutante deberá interponer recurso de apelación en contra de dicho auto, conforme lo prescrito por el artículo 438 del CGP, para que el superior resuelva. Este aspecto es de especial importancia debido a que es en este punto se suscita una dificultad, porque si el ejecutado propone la excepción de cláusula compromisoria y esta prospera, se revocará el mandamiento de pago, frente a lo cual, el ejecutante deberá interponer recurso de apelación, en el evento en que ello resulte procedente, debiendo ir al superior para que lo resuelva. De llegar a ser confirmada la decisión del a quo, se estaría frente a una posible negación de justicia, debido a que la jurisdicción ordinaria le estaría diciendo al ejecutado que no es competente para conocer dicho proceso, en virtud de la cláusula compromisoria pactada por las partes, en la que se comprometieron a resolver los conflictos suscitados con base en este contrato ante un tribunal de arbitramento, encontrando con que al dirigirse al tribunal de arbitramento a resolver su asunto, este le dirá que no están facultados por la ley para conocer procesos de naturaleza ejecutiva.

Si las excepciones no prosperan, el juez debe proferir auto que ordene seguir adelante la ejecución en la forma en que corresponda y se sigue el proceso conforme lo prescrito en los artículos 446 a 472 del CGP.

Otro aspecto de especial importancia en el proceso ejecutivo es el relativo a las medidas cautelares, que consisten en la aprehensión de los bienes que estén en cabeza del deudor y que sean señalados por el demandante. Estas medidas son el embargo y el secuestro, que en algunas circunstancias se dan simultáneamente y a veces de manera separada. Existe otra medida que es la inscripción de la demanda que se da sobre bienes sujetos a registro para que recaiga un gravamen sobre dicho bien.

Debido a la certeza que emana del título ejecutivo, la ley permite la práctica de medidas cautelares, y dicha petición se puede formular junto con la presentación de la demanda o en el transcurso del proceso. Las medidas previas son las que se solicitan antes de que el demandado sea notificado de la existencia del proceso. Todo ello con base en los principios denominados fumus bonis iuris o apariencia del buen derecho y periculum in mora o el peligro que representa la mora para el acreedor de esa obligación.

El CGP consagra en los artículos del 431 a 435, lo que podría denominarse clases de obligaciones sobre las cuales podría versar el proceso ejecutivo, aunque a nuestro juicio el criterio al que se debe acudir para valorar una obligación para ser ejecutable ante la jurisdicción es que conste en un título ejecutivo y que la misma sea clara, expresa y exigible, como se ha reiterado. Las que consagra el CGP son: obligaciones de pagar sumas de dinero, obligaciones de dar, obligaciones de hacer, obligaciones de suscribir documentos y obligaciones de dar; las cuales no se explican debido a que sus nombres enuncian perfectamente su contenido.

\section{ii. Generalidades del proceso declarativo}

Se entiende por proceso declarativo o de cognición aquel en virtud del cual el juez profiere o emite una declaración en la sentencia, habiendo tenido antes conocimiento de los hechos. 
Se denominan declarativos por cuanto la labor del juez está encaminada a declarar la existencia de un derecho o una relación jurídica cualquiera y quienes lo denominan de cognición lo hacen con base en la idea de que el juez conoce unos hechos a través de las pruebas, para posteriormente proferir una decisión sobre el caso (Bejarano, 2008).

La doctrina tiende a dividirlos en declarativos puros, declarativos constitutivos y declarativos de condena, relacionando cada uno con la naturaleza u orientación de las pretensiones:

Declarativos puros: Por medio de este se declara la existencia o no de un derecho.

Declarativos constitutivos: Se busca que una situación jurídica preexistente se modifique por otra.

Declarativos de condena: Es el de más frecuente uso en nuestro ordenamiento, y a través de este se busca que le sea impuesta una condena al demandado.

El artículo 368 de Código General del Proceso señala que se sujetarán al trámite establecido en ese capítulo -procesos declarativos. Título I Proceso verbal-, todo asunto contencioso que no esté sometido a un trámite especial, dejando claro que su aplicación procede cuando no existe un trámite especial previsto en la Ley 1564 de 2012 o en una norma externa especial, para regular y ventilar una controversia determinada, mediando, además, la siguiente consideración: i) que las pretensiones no tengan cuantía, ii) si la tienen, correspondan a menor o a mayor cuantía. En el evento de que corresponda a mínima cuantía, por disposición del artículo 309 de la norma en comento, debe tramitarse a través del proceso verbal sumario.

Las notas esenciales del proceso declarativo apuntan a que la reclamación parte de la incertidumbre o la falta de claridad en la existencia de una relación jurídica o del derecho sustancial alegado, naturalmente, movido por la convicción de que en efecto existe para aquel que promueve la acción. Es decir, la controversia parte del alegato de estar dadas las condiciones o requisitos exigidos para la configuración del derecho o para el surgimiento de la relación jurídica, pero su afirmación no basta más que para impetrar la acción, puesto que es el juez, a partir de la correspondiente valoración probatoria, quien declara la concurrencia de los presupuestos para su surgimiento o reconocimiento. Si se permite la afirmación, en el proceso declarativo no están dadas las condiciones de claridad, exigibilidad y certeza, y hacia esa verificación es que debe estar orientado el debate probatorio.

Sobre la ausencia de certeza en el proceso declarativo, se encuentra que algunos autores lo denominaron proceso de acertamiento (el término acertamiento es una expresión en desuso en la lengua castellana, siendo de más frecuente uso referirse a "acertar" o "generar certeza", sin embargo, se comprende en la definición de Carnelutti que la vocación del proceso declarativo es precisamente generar certeza y declararla, respecto de una situación jurídica determinada.), debido a la finalidad de acertar en los estados jurídicos, o, en otras 
palabras, establecer la aplicación obligatoria de las normas, lograr la certeza del derecho (Carnelutti, 1960). Así, la pretensión declarativa tiene por objeto solicitar una sentencia en la que se declare o se niegue la existencia de determinada relación jurídica respecto de la cual hay incertidumbre, y cuya falta de certeza termina, precisamente, con la declaración que por medio de la sentencia hace el Estado (López, 2002).

Se tiene entonces que mientras en el proceso ejecutivo se posee la certeza, claridad y exigibilidad de la existencia de un derecho y la correlativa obligación de satisfacerlo por parte del demandado, de ahí la valía probatoria del título ejecutivo, en el proceso declarativo se parte de la incertidumbre respecto del derecho o determinada relación jurídica y se busca su declaratoria mediante la sentencia proferida por el Juez.

\section{iii. Sobre el proceso arbitral}

La ley 1563 de 2012, por medio de la cual se expide el Estatuto de Arbitraje Nacional e Internacional y se dictan otras disposiciones, consagra en su artículo primero que: "El arbitraje es un mecanismo alternativo de solución de conflictos mediante el cual las partes defieren a árbitros la solución de una controversia relativa a asuntos de libre disposición o aquellos que la ley autorice".

Se tiene entonces que el arbitraje es un método alternativo de resolución de conflictos que implica que las partes, de común acuerdo, trasladan a un particular, investido transitoriamente de la facultad de administrar justicia, la solución de un diferendo suscitado entre ambos, el cual debe ser de aquellos asuntos de los que se puede disponer o que la ley expresamente los autorice, puesto que existen derechos que son irrenunciables e intransigibles, que naturalmente escapan a la órbita de la voluntad de los sujetos. Es un proceso declarativo que se rige por los principios y reglas de imparcialidad, idoneidad, celeridad, igualdad, oralidad, publicidad y contradicción y termina con un laudo arbitral, que es la sentencia que profiere el tribunal de arbitraje, que a su vez puede ser en derecho, en equidad o técnico.

La Ley 1563 de 2012 contiene disposiciones que dan cuenta de los obstáculos que posee la justicia arbitral para entrar a conocer procesos ejecutivos; es decir, aquellos que parten de la base de la existencia de una obligación clara, expresa y exigible, contenida en un documento que emane del deudor y sea plena prueba en su contra. Tales disposiciones se relacionan con la naturaleza del proceso arbitral, la temporalidad de los árbitros y sus limitadas facultades expresamente señaladas en la ley.

Así pues, en cuanto al término de duración de las facultades de los árbitros, por ejemplo, la ley dispone en su artículo décimo: "Si en el pacto arbitral no se señalare término para la duración del proceso, este será de seis (6) meses, contados a partir de la finalización de la primera audiencia de trámite".

Existen dos requisitos que determinan que una controversia pueda ser sometida a un proceso arbitral: Que se trate de un asunto contencioso y que la controversia sea susceptible de transacción, como se pasa a explicar: 
- Que se trate de un asunto contencioso: Es decir, aquellos asuntos que susciten controversia o conflicto entre las partes.

- Que la controversia sea susceptible de transacción: Es decir, sobre aquellos temas respecto de los cuales las partes puedan disponer, o sea, que no se hallen fuera de la esfera de su libre disposición, que no exista impedimento para decidir particularmente sobre ellos, como el estado civil, por ejemplo.

Sobre las características básicas del arbitramento, resulta ilustrativa la sentencia C-1038 (2002), mediante la cual se resolvió la demanda de inconstitucionalidad contra el artículo 13 del Decreto 2651 (1991), adoptado como legislación permanente por el artículo 162 de la ley 446 (1998); contra el artículo 15 del Decreto 2651 (1991), adoptado como legislación permanente por el artículo 162 de la ley 446 (1998), y cuyos numerales $3^{\circ}$ y $4^{\circ}$ fueron modificados por el artículo 119 de la ley 446 (1998); y contra los artículos 119, 121 y 122 de la ley 446 (1998).

La mencionada sentencia señala las siguientes características:

i) es uno de los instrumentos autorizados para que los particulares puedan administrar justicia, ii) están regido por el principio de habilitación o voluntariedad, pues el desplazamiento de la justicia estatal por el arbitramento tiene como fundamento un acuerdo previo de carácter voluntario y libre efectuado por los contratantes; iii) el arbitramento es temporal, pues la competencia de los árbitros está restringida al asunto que las partes le plantean, iv) el arbitramento es también de naturaleza excepcional, pues la Constitución impone límites materiales a la figura, de suerte que no todo problema jurídico puede ser objeto de un laudo, ya que es claro que existen bienes jurídicos cuya disposición no puede dejarse al arbitrio de un particular, así haya sido voluntariamente designado por las partes enfrentadas; y, finalmente, v) la Corte ha destacado que la voluntariedad del arbitramento no excluye que la ley regule la materia, pues el arbitramento es un verdadero proceso, a pesar de que sea decidido por particulares, y por ello está sujeto a ciertas regulaciones legales, en especial para asegurar el respeto al debido proceso.

\section{iv. La cláusula compromisoria}

Según el artículo $4^{\circ}$ de la ley 1563 (2012), la cláusula compromisoria, podrá formar parte de un contrato o constar en documento separado inequívocamente referido a él. La cláusula compromisoria que se pacte en documento separado del contrato, para producir efectos jurídicos deberá expresar el nombre de las partes e indicar en forma precisa el contrato a que se refiere.

Como se ha venido reiterando, la cláusula compromisoria contractual es una estipulación inserta en el contrato, en virtud de la cual las partes manifiestan su voluntad de resolver los conflictos originados en dicho contrato, ante un tribunal de arbitramento, buscando su solución a través de los mecanismos alternativos de solución de conflictos y, por tanto, sustrayéndolos del aparato judicial y de su poder coactivo. 
Adrián Barreto Lezama

El ideal de todo conflicto con relevancia jurídica, es que pudiera resolverse con la sola apelación a las normas jurídicas, pero es claro que las dinámicas individuales y sociales dictan lo contrario y muestran que la sola existencia de las normas no implica el acatamiento obediente por parte de los administrados. Es por ello, que las normas jurídicas tienen la prerrogativa de garantizar su cumplimiento mediante el empleo de la coacción. Bajo ese entendido, el desconocimiento de las normas conlleva la imposición de una sanción correspondiente. En todo caso, el ordenamiento jurídico prevé una consecuencia negativa para el sujeto que se abstiene de cumplir la norma, genéricamente hablando. Las normas jurídicas, consideradas como instrumento de control social, deben prever el escenario de su desconocimiento.

Estas notas sobre el poder coactivo de las normas jurídicas, apareja indiscutiblemente, una garantía de seguridad jurídica para los asociados, debido a que defiende las certezas sobre las cuales se construyen las relaciones jurídicas en la sociedad, a la par que van dando luces sobre las limitaciones que tienen los particulares -aun los investidos temporalmente de funciones jurisdiccionales-, de administrar esa coercibilidad, que en los modelos democráticos requiere que su radicación esté en cabeza del poder institucional del Estado, empleando como límites legítimos la Constitución Política y la ley.

El modelo democrático también impone que ese poder coactivo de las normas jurídicas, administrado por el Estado, obedezca a ciertas formalidades que garantizan derechos y principios superiores, y que tienen su fuente en la misma Constitución y en las leyes. Una de esas formas del poder coercitivo que respaldas a las normas jurídicas, es el que ejerce el aparato jurisdiccional en ejercicio de la función judicial, cuyas "formas" de administración están dadas por las formas procesales aplicables a cada asunto en concreto, y que garantizan la ritualidad por la que cursa el proceso, y por esa misma vía, la satisfacción de los postulados de las normas sustanciales.

Como se ha venido indicando, el poder coactivo, por un asunto de seguridad jurídica, debe estar radicado en cabeza del Estado, de manera permanente, pues dada su magnitud, su ejercicio se legitima en las formas propias del proceso, pero, sobre todo, en las potestades expresamente conferidas a los jueces en virtud de la Constitución y las leyes. Ahora, ello no es óbice para reconocer el valor de materializar los propósitos del artículo 116 de la Constitución Política de Colombia, en virtud del cual la función jurisdiccional puede ser temporalmente atribuida a los particulares. Sin embargo, no se trata de cuestionar el ejercicio de dicha función por los particulares, si no, el de la exclusiva prerrogativa de coacción, la cual sustenta la naturaleza del proceso ejecutivo, al no existir dudas sobre la existencia y exigibilidad del derecho, contrario a lo que ocurre en el proceso declarativo. En otras palabras, quien acude ante un juez a demandar por la vía del proceso ejecutivo, con base en un documento que presta tal mérito, no lo hace para marcar una controversia, si no en busca de la intervención del poder del Estado, materializado en la función judicial, para hacer efectivo el derecho que ya tiene.

Es crucial la comprensión de este asunto, pues nos enfrenta a la imposibilidad de que, por virtud del acuerdo de voluntades, no de la constitución o la ley, se les atribuyan a los particulares, árbitros o conciliadores, poderes de coacción. 
En efecto, la carencia del poder coactivo por parte de los árbitros puede evidenciarse a partir de la revisión de algunas normas que regulan la materia, por ejemplo, del inciso $2^{\circ}$ del artículo $1^{\circ}$ del Decreto 2279 (1989), modificado por el artículo 96 de la ley 1563 (2012), que señala que "los aspectos de ejecución que demanden las condenas en los laudos deberán tramitarse ante la jurisdicción ordinaria". Asimismo, el artículo 40 de la misma ley, el cual desarrolla lo relativo a la oportunidad para dictar el correspondiente laudo arbitral y la consignación en el mismo de la liquidación de las costas y demás condenas a las partes, dispone en su parágrafo único que la ejecución de dicho laudo será de conocimiento de la justicia ordinaria, conforme a las reglas generales.

Por su parte, la Corte Suprema de Justicia (1994), al defender la imposibilidad de resolver procesos de ejecución en los tribunales de arbitramento, ha sostenido:

\begin{abstract}
"Sin embargo, excepcional y transitoria e individualmente se permite que el Estado delegue su función en administrar justicia en particulares, como en los árbitros (Art. 116, inc. Final. C. N.), de acuerdo con la ley y precisamente la ley actualmente vigente continúa con el criterio tradicional de reserva por parte del Estado del poder jurisdiccional de ejecución, debido a su esencia coercitiva y coactiva de las órdenes, y medios y medidas que en ella deben aplicarse; razón por la cual se excluye de la posibilidad de cláusula compromisoria, compromiso y arbitraje los asuntos de ejecución".
\end{abstract}

En esta misma sentencia, la Corte Suprema de Justicia indicó que los procesos de ejecución son competencia exclusiva del Estado y que, si bien la cláusula compromisoria se puede extender a las diferencias que se susciten entre las partes durante la ejecución del contrato, no puede predicarse lo mismo de la ejecutabilidad del contrato como título ejecutivo. En el mismo sentido, la Corte Suprema ha señalado que el debido proceso tiene como regla imperativa el adelantamiento de los procesos ante el juez competente, siendo el Estado, el titular nato del poder jurisdiccional, pudiendo excepcional y transitoriamente, delegar esa función en particulares, como son los árbitros. Dicho de otra manera, el Estado se reserva el poder jurisdiccional de ejecución y, el arbitramento jamás impide a las partes adelantar antes los jueces ordinarios los procesos de ejecución.

Por último, se debe indicar que en el marco del proceso arbitral no resulta posible la práctica de medidas cautelares de embargo y secuestro, como se expuso en el primer aparte del este escrito, pues que la ley solo prevé la posibilidad de adelantar en el marco de este, la inscripción del proceso en cuanto a los bienes sujetos a registro.

\title{
i. CONCLUSIONES
}

La cláusula compromisoria no resulta procedente como excepción en el proceso ejecutivo debido a que, aun habiendo pactado voluntariamente resolver las diferencias surgidas en virtud del contrato ante un tribunal de arbitramento, la naturaleza del proceso ejecutivo y las facultades que en el marco del mismo se le atribuyen al juez, están exclusivamente asignadas a los jueces, lo que impone límites para su conocimiento por parte de los árbitros. Principalmente, porque el proceso arbitral es un proceso de conocimiento, es decir, implica valoración de la prueba, y a partir de esta, declarar la existencia del derecho o la 
configuración de la relación jurídica, lo que no ocurre en el proceso ejecutivo, en el cual no solo existe la obligación, sino que la misma se tiene como clara, expresa y exigible.

Por otra parte, el poder coactivo del Estado no puede ser asignado a los particulares en virtud del acuerdo de voluntades, pues como prerrogativa estatal de garantía de cumplimiento de las normas jurídicas y de los derechos que de ellas emanan, surgen por mandato constitucional o legal, lo mismo que los límites y alcances de su ejercicio. Esto se erige como un asunto vertebral, por cuanto el proceso ejecutivo se cimenta sobre ese poder coactivo, puesto que si alguien acude ante un juez a solicitar que se haga efectivo un derecho que emana de un título ejecutivo, se parte de la base de la renuencia del deudor a satisfacer ese derecho. En ese escenario, el poder de obligar a ese sujeto renuente a cumplir con su obligación, no ya a declarar la existencia de la misma, requiere plena atribución de facultades coactivas, las cuales no están asignadas a los árbitros en virtud de ley alguna, mucho menos de la Constitución.

En ese mismo sentido se encuentran límites al ejercicio de las medidas cautelares, lo que reafirma la ausencia de ese poder coactivo, puesto que -por mandato legal- en el proceso arbitral solo es procedente la inscripción del proceso frente a aquellos bienes sujetos a registro, y quedan excluidas las medidas de embargo y secuestro, quizá las más efectivas para compeler al deudor a que pague, por tanto, las de mayor uso en el marco del proceso ejecutivo.

Aceptar la procedencia de la excepción de cláusula compromisoria, como excepción en el marco del proceso ejecutivo, contraría el debido proceso y comporta una eventual negación de justicia, debido a que el acreedor entrará en un círculo vicioso al acudir ante un tribunal de arbitramento, habiéndose declarado probada la excepción en el proceso ejecutivo, para que en esa sede se constate que los árbitros no tienen facultades de ejecución y que en efecto no disponen de los poderes cautelares que garanticen la satisfacción de la acreencia.

\section{REFERENCIAS BIBLIOGRÁFICAS}

Bejarano Guzmán, R. (2008). Procesos declarativos. Bogotá, Colombia: Ed. Temis.

Carnelutti, F. (1960). Instituciones del proceso civil II. Buenos Aires, Argentina: Librería El Foro.

Código General del Proceso. Ley 1564 de 2012. Julio 12 de 2012. (Colombia).

Congreso de la República. Ley 1563 de 2012. Por medio de la cual se expide el Estatuto de Arbitraje Nacional e Internacional y se dictan otras disposiciones. Julio 12 de 2012. (Colombia).

Congreso de la República. Ley 270 de 1996. Por medio de la cual se aprueba la Ley Estatutaria de la Administración de Justicia. Marzo 15 de 1996. D.O. $\mathrm{N}^{\circ} 42.745$. (Colombia). 
Constitución Política de Colombia. Art. 116. Julio 7 de 1991 (Colombia).

Corte Constitucional. Sala Plena. Sentencia C-1038 de 2002. [M.P Eduardo Montealegre Lynett; noviembre 28 de 2002].

Corte Suprema de Justicia. Sala Civil. Expediente 1566 de 1994. [M.P. Pedro Lafont Pianetta; septiembre 23 de 1994]

Corte Suprema de Justicia. Sentencia STC3298 del 2019. Radicación N 25000-22-13-0002019-00018-01. [M.P Luis Armando Tolosa Villabona; marzo 14 de 2019]

Echandía, H. (1991). El proceso civil. Parte especial. Bogotá, Colombia: Ed. Temis.

Kalach Torres, G. Las comisiones de la verdad en Colombia. En Revista Jurídica Mario Alario D'Filippo, vol. 8, núm. 16, p. 106-124, 2016. Recuperado de: https://doi.org/10.32997/2256-2796-vol.8-num.16-2016-1534

López Blanco, H. (2002). Procedimiento Civil. Parte General. Bogotá, Colombia: Dupré Editores.

López Blanco, H. (2016). Código general del proceso. Bogotá, Colombia: Dupré Editores.

Luna Salas, F. (2019). Hechos, Verdad y Prueba. En F. Luna y E. de Río. Compendio de Derecho Probatorio Contemporáneo, p. 39-59. Bogotá, Colombia: Grupo Editorial Ibáñez.

Luna Salas, F. (2019). Técnicas neurocientíficas como medio de prueba pericial. Revista Prolegómenos. Vol. 22, Número 44: 143-154 DOI: https://doi.org/10.18359/prole.4160

Monroy Cabra, M. Procesos ejecutivos, declarativos y cautelares. En Revista del Instituto Colombiano de Derecho Procesal, vol. 2, núm. 2, 1984. Recuperado de: http://publicacionesicdp.com/index.php/Revistas-icdp/article/view/355

Presidencia de la República de Colombia. Decreto 2279 de 1989. Por el cual se implementan sistemas de solución de conflictos entre particulares y se dictan otras disposiciones. Octubre 7 de 1989.

Rosemberg, L, (1955). Tratado de derecho procesal civil. Tomo III. Buenos Aires, Argentina: Ediciones Jurídicas Europa América.

Viguri Perea, A. y Chiara Marullo, M. El derecho a un medio ambiente sano y la encrucijada de los alimentos transgénicos. En Revista Jurídica Mario Alario D'Filippo, vol. 8, núm. 15, p. 100-111, 2016. Recuperado de: https://doi.org/10.32997/2256-2796vol.8-num.15-2016-1526 